\title{
Hyperspectral data in water stress detection
}

\author{
Riczu, P., Nagy, A. \& Tamás, J. \\ University of Debrecen, Institute of Water and Environmental Management, Debrecen, \\ 4032 Böszörményi str.138.attilanagy@agr.unideb.hu
}

\begin{abstract}
Summary: Remote sensing methods are applied widespread to investigate large land fields. Within these methods the status of certain vegetation can be determined based on the reflectance spectra of the chlorophyll, in order to support agriculture, forestry and the evaluation of soil pollution. The main aims of our study were to determine and validate the reflectance spectra of fruit tree species, in order to facilitate the identification and evaluation of stressed fruit trees in orchards.
\end{abstract}

Keywords: hyperspectral remote sensing, orchard, water stress

\section{Introduction}

Technologies of precision agriculture are playing an increasingly important role in agricultural and fruit production in order to enhance high quality of production under environmentally compatible management (Auernhammer 2001; Tian 2002; Gerhards and Sökefeld 2003; Khosla et al. 2006). The hyper- and multispectral technology is widely used in the precision agriculture (Burai, 2009; Milics et al. 2008), field growing of plants, and nowadays in gardening culture (Nagy and Tamás. 2013). Hyperspectral imagery is also appropriate for vegetation analysis The chlorophyll content is one of the indicators of the state of health before ripening phenological phase, which could be estimated by vegetation mapping technologies (Haboudane et al. 2002; Burai et al. 2009). Minimum at the visible spectral range is related to pigments in plant leaves. Chlorophyll absorbs markedly spectral range between $450-670 \mathrm{~nm}$. Reaching infrared spectral range, the reflectance of healthy vegetation increases rapidly. Healthy vegetation reflects the $40-50 \%$ of the incoming energy between $700-1300 \mathrm{~nm}$ spectral ranges due to the internal structure of the canopy. In this way, the measured reflectance plays an important role in distinguishing different plant species, even if these species are seems to be similar based on visible spectral range (Berke et al. 2004). Vegetation mapping has been widely used in agriculture cropping with the help of remote sensing or hyperspectral technology (Lamb and Brown 2001; Menges et al. 1985; Tits et al. 2003). The "hyper" in hyperspectral refers to the large number $(>498)$ of measured wavelength bands. Field and laboratory spectrometers usually measure reflectance at many narrow, closely spaced wavelength bands, so that the resulting spectra appear to be continuous curves. The Normalized Difference Vegetation Index (NDVI) is one of the vegetation indices that have been commonly used in remote-sensing applications in agriculture to detect trees foliage or different type of vegetation (Santoro et al. 2013).

\section{Materials and methods}

The research was carried out at the University of Debrecen, Centre for Agricultural and Applied Economic Sciences, Research Institute for Farm and Regional Research Sciences at Pallag. The examination site is a microirrigated intensive apple orchard. The orchard is $0.68 \mathrm{ha}(62 \mathrm{~m} \mathrm{x} 110 \mathrm{~m})$ with $4 \mathrm{~m}$ row and $1 \mathrm{~m}$ tree distance. All species were grafted on M9 stocks. The main aims of our study were to determine and validate the reflectance spectra of fruit tree species, in order to facilitate the identification and evaluation of stressed fruit trees in orchards.

In 2006, an AISA DUAL airborne hyperspectral cam system were installed and operated in cooperation the University of Debrecen, AMTC, Department of Water and Environmental Management with the Mechanization Institute of Agricultural Ministry in Gödöll . The most important parts of the hyperspectral sensors are the spectrograph, which dissolve the electric waves arrived through the optical rift with the help of prisms and optical screen. The hyperspectral sensor consists of one optic, one spectrograph and one digital cam. The two hyperspectral sensors are assemble in a house, therefore it is known ASIA DUAL system. The two cams can perceive in the visible wavelength, near infrared range and short wave infrared range. The Eagle camera takes images in visible and near infrared range (VNIR), while Hawk operates in the middle infrared range (SWIR). By means of establishing of two camera a DUAL system were installed. The full range $400-2450 \mathrm{~nm}$, which can be set $1.25-10 \mathrm{~nm}$ wavelength band and maximum 498 spectral channels. Two sensors can also be operated separately, so it makes possible to utilize the wider wavelength of higher resolution (1024 pixels) VNIR sensor. The hyperspectral evaluation and NDVI calculation was carried out with ENVI software programme.

In order to validate NDVI values, pigment content were also measured. Fresh leaf samples were used for pigment measurements. The weight of leaf samples were about 80 - 
$100 \mathrm{mg}$, leaves were destructed by $10 \mathrm{ml}$ acetone for extraction and $1 \mathrm{~g}$ quartz sand for homogeneity. After extraction the suspensions were centrifuged, and the absorbance of the clean solution was measured by SECOMAN Anthelie Light II. UV-VIS spectrophotometer at 644 and $663 \mathrm{~nm}$ wavelength. Based on the absorbances chlorophyll content was calculated by the followings (Droppa et al., 2003):

\section{Chlorophyll $(a+b) \mu \mathrm{g} / \mathrm{g}$ fresh} weight $=(20,2 * A 644+8,02 * A 663) * V / w$,

where: $\mathrm{V}=$ volume of tissue extract $(\mathrm{ml}), \mathrm{w}=$ fresh weight of tissue $(\mathrm{g}), \mathrm{A}=$ absorbance.

\section{Results and discussion}

An image extract was taken form the hyperspectral image containing the extended environment of the apple plantation. Spectra were collected at several representative point of sample area in the cause of analyzing spectral curves. The smaller foliage trees are characterized by lower reflectance curves, while greater foliages are joint to higher and higher values among well separating curves on the spectral profile. The spectral profile shows the spectral value regarding to 1 pixel $\left(2.25 \mathrm{~m}^{2}\right)$ as a function of foliage in case of all channels. On the picture it can be seen that the foliage separates marked in infrared range between 773-782 $\mathrm{nm}$ (Figure 1.).

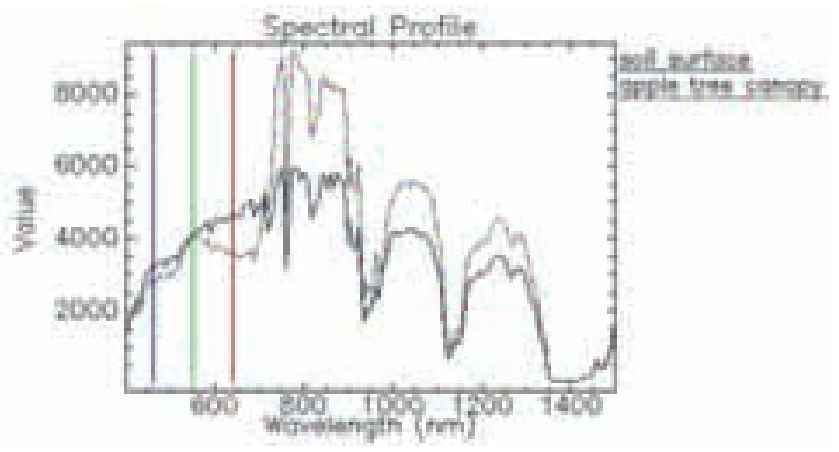

Figure 1. Spectral profile of soil and canopy

Based on the spectral data of the examined site NIR and RED intervals were examined. These intervals are important in vegetation classification, since the highest variance is found in this region. Based on the scatter plot of the orchard well defined groups can be separated from each other, with which image classification was carried out. Rows, farm roads and row spaces, concrete surfaces and forest sites were eliminated in the orchards and in its neighborhood (Figure 2.). The importance if classification is that certain surfaces can be eliminated for further studied.

After that the utilization of water sensitive Water Band Index was evaluated. The Water Band Index (WBI) is a reflectance measurement that is sensitive to changes in canopy water status. As the water content of vegetation canopies increase, the strength of the absorption around
$970 \mathrm{~nm}$ increases relative to that of $900 \mathrm{~nm}$. WBI is defined by the following: $\mathrm{WBI}=\delta_{900} / \delta_{970}$ (Champagne et al. 2001). In accordance with the study of Tamás and Szabó (2010), channel with $900 \mathrm{~nm}$ is found to be a sensitive water stress indicator, although the minimum value of the first derivative of the reflectance curve was at 930-940 $\mathrm{nm}$ wavelength interval. The $970 \mathrm{~nm}$ channel provided less usable values as a denominator for WBI.

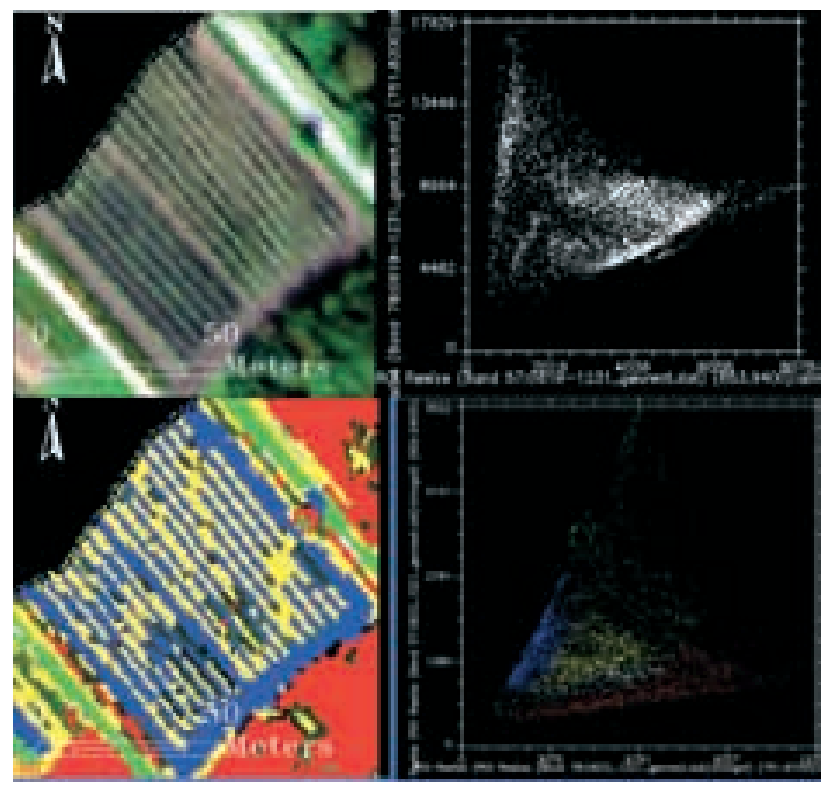

Figure 2. Apple orchard and scatter plot of NIR and RED and their classification images

Normalized Difference Vegetation Index (NDVI) was calculated as well, which shows close connection with chlorophyll content, with using near infrared (NIR: 730-1100 $\mathrm{nm}$ ) and red (R: 580-680 nm) wavelength ranges. The value of the index is between -1 and 1 . In case of green vegetation the value of the index is $0.2-0.8$. The real value of the apple orchard in Pallag are the followings: $\min .=0.14$; $\max .=0.89$ (Figure 3.)

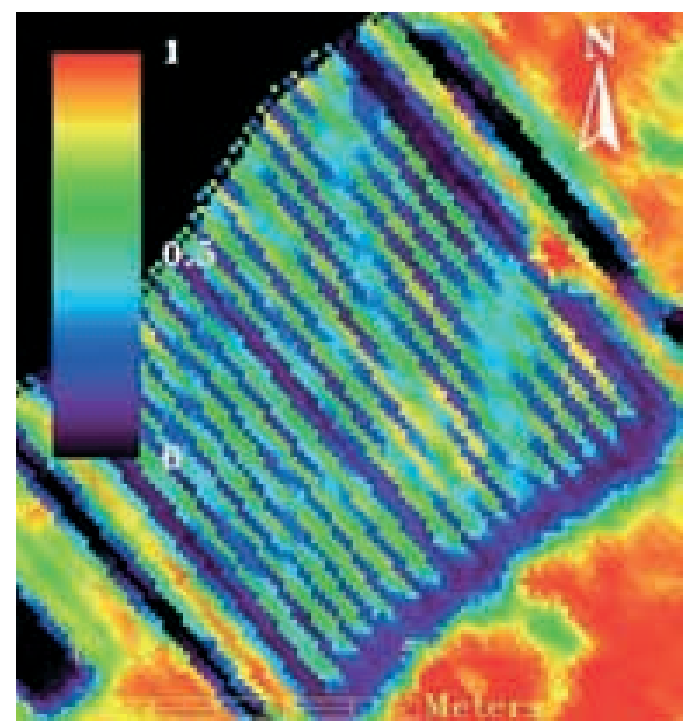

Figure 3. NDVI of the apple orchard 
Concerning directly the fruit tree rows the NDVI properties of the orchard canopy can be defined more precisely. In order toachive this mask was built for vegetation and pixels withot any vegetation coverage were eliminated from the image and the main NDVI statiscal parameters could be calculated (Table 1.).

Table 1. NDVI value of apple trees in

\begin{tabular}{|c|c|c|c|}
\hline Mean & Standard dev. & Min & Max \\
\hline 0.537 & 0.071 & 0.394 & 0.621 \\
\hline
\end{tabular}

Correlating NDVI data with chlorophyll data of leaf samples from the orchard significant correlation was not found within $95 \%$ confidence. This is hardly due to the spectral mixing of canopy, which means that spectral feature is not only represents the certain tree, but the neighbouring features of trees, and even weed or barren sandy soil surface in row space This spectral mixing is fluctuating between $0-45 \%$ pixel by pixel. Despite this fact pixels representing different biomass production can be selected. Therefore correlation was examined within $90,85,80$ and $75 \%$ confidence, and it is found that proof results can be achived at $20 \%$ error ( $80 \%$ confidence). The importance of this is that the amount of chlorophyll content are in strong relationship with biomass production and evapotranspiration properties, thus the results can facilitate to define the vegetation pattern $\left(\mathrm{k}_{\underline{\underline{c}}}\right)$ value more precisely.

\section{Acknowledgments}

This research was supported by the European Union and the State of Hungary, co-financed by the European Social Fund in the framework of TÁMOP 4.2.4. A/2-11-1-20120001 'National Excellence Program'.

\section{References}

Auernhammer, H. (2001): Precision farming — the environmental challenge. Computers and Electronics in Agriculture. 30 (1-3): 31-43.

Berke, J., D. Kelemen, and J. Szabó. (2004): Digitális képfeldolgozás és alkalmazásai. (Digital image processing and application) PICTRON Kft., Keszthely, Hungary

Burai, P., Kovács, E., Lénárt, Cs., Nagy, A., Nagy, I. (2009): Quantification of vegetation stress based on hyperspectral image processing. Cereal Research Communications. 37: 581-584.
Champagne, C. A., Pattey, E., Bannari, A., Stratchan, I.B. (2001): Mapping Crop Water Status: Issues of Scale in the Detection of Crop Water Stress Using Hyperspectral Indices. Proceedings of the 8th International Symposium on Physical Measurements and Signatures in Remote Sensing. Aussois. France. pp.79-84.

Droppa M., Erdei S., Horváth G., Kissimom J., Mészáros A., Szalai J., Kosáry J. (2003): Növénybiokémiai és növényélettani gyakorlatok. Budapest

Gerhards, R. and Sökefeld. M. (2003): Precision farming in weed control-system components and economic benefits. Precision Agriculture. eds. J. V. Stafford and A. Werner, 229-234. Netherlands, Wageningen Academic Publishers.

Haboudane, D., Miller, J. R., Tremblay, N., Zarco-Tejada P. J., Dextrazec, L. (2002): Integrated narrow-band vegetation indices for prediction of crop chlorophyll content for application to precision agriculture. Remote Sensing of Environment. 81 (2-3): 416-426.

Khosla, R., Westfall. D., Reich, R., Inman, D. (2006): Temporal and Spatial Stability of Soil Test Parameters Used in Precision Agriculture. Communications in Soil Science and Plant Analysis. 37: 2127-2136.

Lamb, D.W. and Brown. R.B. (2001): Remote-Sensing and Mapping of Weeds in Crops. Journal of Agricultural Engineering Research. 78 (2): 117-125.

Menges, R.M., Nixon, P.R., Richardson, A.J. (1985): Light reflectance and remote sensing of weeds in agronomic and horticultural crops. Weed Science. 33 (4): 569-581.

Milics, G., P. Burai, and Cs. Lénárt (2008): Pre-Harvest Prediction of spring barley nitrogen content using hyperspectral imaging. Cereal Research Communications, Supplement: 18631866.

Nagy, A. Tamás, J. (2013): Non-invasive water stress assessment methods in orchards. Soil Science and Plant Analysis, 44 (1-0): 366-376

Santoro, F., Tarantino, E., Figorito, B., Gualano, S., D’Onghia A. M. (2013): A tree counting algorithm for precision agriculture tasks. International Journal of Digital Earth. 6 (1): 94-102.

Tamás, J., Szabó, Z. (2010): Hyperspectral evaluation of the pear trees ont he basis of genetic collection of different speies. [In Wagner, W., Székely, B. (eds.) International Society for Photogrammetry and Remote Sensing (ISPRS)] TC VII. Vienna, Austria, July 5-7: 563-567.

Tian, L. (2002): Development of a sensor-based precision herbicide application system. Computers and Electronics in Agriculture. 36 (2-3): 133-149.

Tits, L., Somers, B., Stuckens, J., Farifteh, J., Coppin, P. (2013): Integration of in situ measured soil status and remotely sensed hyperspectral data to improve plant production system monitoring: Concept, perspectives and limitations. Remote Sensing of Environment. 128: 197-211. 